\title{
The Economic Burden of Head and Neck Cancers in Denmark
}

\author{
Jens Olsen ${ }^{1,2 *}$, Tine Rikke Jørgensen ${ }^{3}$, Niclas Rubek ${ }^{4}$ \\ ${ }^{1}$ University of Southern Denmark, Odense C, Denmark \\ ${ }^{2}$ Incentive, Holte, Denmark \\ ${ }^{3}$ Sanofi Pasteur MSD ApS, Kongens Lyngby, Denmark \\ ${ }^{4}$ Rigshospitalet, Copenhagen, Denmark \\ Email: ${ }^{*}$ jo@incentive.dk
}

Received January 29, 2013; revised March 3, 2013; accepted April 1, 2013

Copyright (C) 2013 Jens Olsen et al. This is an open access article distributed under the Creative Commons Attribution License, which permits unrestricted use, distribution, and reproduction in any medium, provided the original work is properly cited.

\begin{abstract}
Introduction: The incidence of head and neck cancers has increased markedly over the last decade. A Danish study of the costs of head and neck cancers has not been undertaken. Such studies have again become relevant due to the development of the HPV vaccines, as some cases are attributable to high-risk HPV 16 or 18. The objective of the study was to estimate the incidence of head and neck cancers and their health care costs. Methods: Data on incidence and health care use related to head and neck cancer were obtained from Danish health care registers. New cancer patients were identified in the Danish National Cancer Register. Resource use per year in the hospital sector was estimated using data from the National Patient Register applying charges as cost estimates. Health care consumption by cancer patients was compared with that by an age- and sex-matched cohort without cancer. Results: We found that nearly 1000 new cases of oral cavity, oropharyngeal, hypopharyngeal and laryngeal cancer are diagnosed annually. In total the cost of these cancers to the Danish hospital sector constituted 31.6 million Euros per year, with the majority of costs (74\%) occurring in men. The total costs associated with HPV16/18-related head and neck cancers were estimated to be 6.1 million Euros per year. Conclusion: This study provides the first Danish estimates of the costs associated with non-cervical and non-genital HPV-related cancers based on very reliable, individual-based data. It is expected that the current HPV vaccination programme will reduce this burden.
\end{abstract}

Keywords: Head and Neck Cancer; Cost-of-Illness; Human Papilloma Virus (HPV) Infections

\section{Introduction}

The incidence of head and neck cancers has increased markedly over the last decade. A 22\% - 32\% increase has been reported for Denmark since 2001 [1], while an estimated 354,300 new cases and 179,600 deaths from head and neck cancers (including lip cancer) occurred worldwide in 2008 [2]. Head and neck cancers originate from the upper aerodigestive tract, including the oral cavity, oropharynx, nasopharynx, hypopharynx, larynx, salivary glands and other sites located in the head and neck area.

Treatment of head and neck cancer depends on the initial localization of the tumour, on the patient's comorbidity (patients frequently suffer from other co-morbidities) and on the potential side effect of the treatment [3]. Obviously, the patients' emotional, social and physical func-

${ }^{*}$ Corresponding author. tioning are affected by the disease and especially for head and neck cancer patients problems with swallowing, speech, taste/smell, dry mouth, sticky saliva and coughing are also present leading to decreased quality of life.

Smoking, alcohol use and human papilloma virus (HPV) infections are the major risk factors for head and neck cancers, with smoking and alcohol having synergistic effects [4,5]. Head and neck cancers related to HPV are likely to be a distinct entity from those primarily caused by the use of tobacco and alcohol [6-8], although the latter may act as co-risk factors [9,10].

The burden of disease and the costs of head and neck cancers have been estimated for some countries (the US, UK, Greece, Germany, the Netherlands and France) $[3,11,12]$, but the analyses for all except the French study were published more than 10 years ago. A Danish study of the costs of head and neck cancers has not been undertaken. Such studies have again become relevant due to 
the development of the HPV vaccine. Implementation of a HPV vaccination programme is expected to reduce the incidence of HPV-related head and neck cancers in the long-term, as $16 \%$ - $28 \%$ of some head and neck cancers may be attributable to HPV and, among these cases, $86 \%$ $100 \%$ are attributable to high-risk HPV 16 or 18 [13].

The aim of this register-based study was to estimate the incidence of head and neck cancers and their health care costs from a hospital perspective. The results will be used as input into a forthcoming cost-effectiveness analysis of HPV-related cancers and genital warts with the overall objective of estimating the impact of different vaccination programmes.

\section{Methods}

Data on incidence and health care use related to head and neck cancer were obtained from Danish health care registers. Each Danish citizen's contact with the primary health sector (e.g. general practitioner, public and private specialist, dentist, physiotherapist, chiropractor), secondary health sector (e.g. hospital outpatient visits, admissions) and use of prescribed medicine is recorded routinely and can be linked via a unique registration number for each citizen. Danish legislation permits researchers and others to access the databases. The present study was reported to, and approved by, the Danish Data Protection Agency (J. No. 2010-41-4305).

New cancer patients in the period 2004-2007 were identified via specific ICD-10 diagnosis codes in the Danish National Cancer Register. Head and neck cancers were limited to include oral cavity, oropharyngeal, hypopharyngeal and laryngeal cancer as the primary localisation. The following ICD-10 codes were used: C00, C02-C06 (oral cavity cancer), C01, C09-C10 (oropharyngeal cancer), C12-C13, C14.0 \& C14.1 (hypopharyngeal cancer) and C32 (laryngeal cancer).

Resource use per year in the hospital sector was estimated using data from the National Patient Register. The study applied a hospital sector perspective as these cancer types are almost exclusively diagnosed and treated at hospitals.

Health care consumption during 2006-2008 by the cohort of cancer patients was compared with that used by an age- and sex-matched cohort free of cancer (controls). Controls were included so as to identify health care costs related to head and neck cancers (i.e. average cost for cancer patients minus average costs for controls) and health care costs related to other diseases (i.e. average costs for controls) [14]. The cost attributable to head and neck cancers was estimated as the mean difference in costs between the cancer patients and the controls using a two-part generalised linear regression model (GLM) (i.e. we estimated the extra cost for the cancer patients com- pared with the controls). A two-part model was used because a substantial number of the control patients incurred no health care costs) [15-18]. In the results section, only cost estimates attributable to head and neck cancers are presented. By combining a cross-sectional and a longitudinal approach, we could estimate the costs $0-12$ months before the date of diagnosis (e.g. 2006 resource use data for a patient diagnosed in 2007) and the costs 0 12 months, 13 - 24 months (e.g. 2008 resource use data for a patient diagnosed in 2006) and 25 - 36 months after the date of diagnosis (e.g. 2008 resource use data for a patient diagnosed in 2005).

Results are presented as annual cost estimates for the year before, the 1st year, the 2nd year and the 3rd year after the date of diagnosis for patients alive, as well as estimates for the total cost per patient (per patient course). All costs are presented in Euros and future costs (i.e. cost estimates for the 2nd and 3rd years after the date of diagnosis) were discounted using a $3 \%$ annual discount rate in order to present the cost estimates as their present value. Costs for the year before the date of diagnosis were included to cover the costs of initial examination and diagnostic tests. When estimating the total average health care cost per patient (as in Table 1), we adjusted for deaths during the observation period.

Resource use in the hospital sector was defined in terms of registered hospital contacts and included medication during hospital contacts, radio- and chemotherapy and specialised rehabilitation. The resource use associated with each contact was defined according to the Diagnosis Related Groups (DRG) system for hospital admissions and the Danish outpatient (DAGS) charges for outpatient visits (which included emergency unit contacts) [19]. The 2008 DRG and DAGS charges were used as cost estimates.

Data were analysed using SAS software version 9.2 (SAS Institute Inc., Cary, NC, USA).

\section{Results}

Cancer of the oral cavity was the most frequent of the four head and neck cancers and the incidence of all four cancer types was higher among men than women (Table 2). Figure 1 demonstrates that the incidence of cancers in the oral cavity, larynx and hypopharynx increases until age group 60 - 69 years after which it decreases, whereas the incidence of oropharyngeal cancer peaks at the age of 50 - 59 resulting in a higher proportion of patients under 65 years (73\%, cf. Table 2$)$.

After 24 months $61 \%, 63 \%, 45 \%$ and $70 \%$ of the patients with cancer of the oral cavity, oropharynx, hypopharynx and larynx, respectively, were alive. However, these results cannot be interpreted as 2-year survival as the patients may have died from other causes. Estimated 


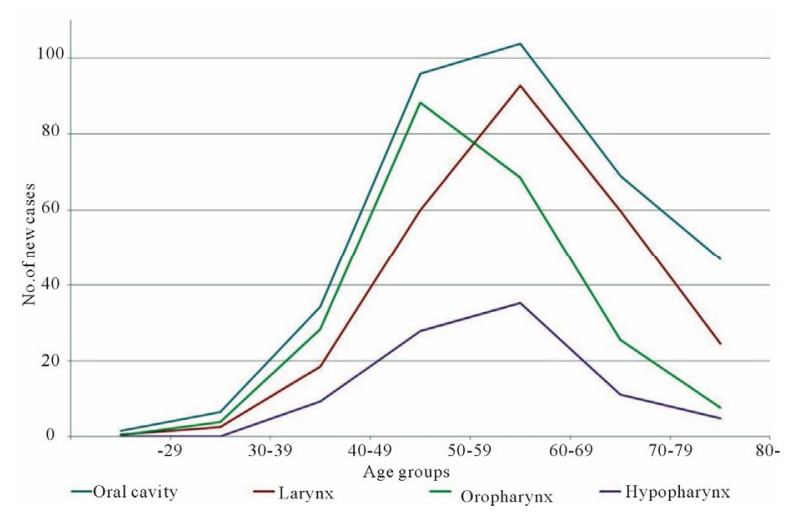

Figure 1. Mean annual incidence of four head and neck cancers (2004-2007).

hospital sector costs were highest the first 12 months after diagnosis and then decreased in the second and third years after diagnosis (Table 3). The cost of hypopharyngeal cancer tended to be higher than for the other head and neck cancer. The costs for male patients with oral cavity cancer tended to be higher than for women in all periods, whereas no systematic trends were seen for the other cancer types.

From the results in Table 3, the total average costs per patient were estimated and are shown in Table 1. Total average cost per patient was highest for hypopharyngeal cancer, especially in women. Total average cost per patient was lowest for oral cavity cancer (though it should be noted that very few women are diagnosed with hypopharyngeal cancer, which results in relatively wide confidence intervals, see Table 3). In total the cost of these four head and neck cancers to the Danish hospital sector constituted 31.6 million Euros per year, with the majority of costs (74\%) occurring in men and corresponding to 23.4 million Euros per year. Relatively, the costs associated with oral cavity cancer constitute $35 \%$ followed by larynx cancer and oropharynx cancer which constitute 29\% and 25\%, respectively (cf. Figure 2).

Using data on HPV prevalence in oral cancer, presented in Table 4, costs attributable to HPV16 and 18 were estimated and are shown in Table 1. The total costs associated with HPV16/18-related head and neck cancers were estimated to be 6.1 million Euros per year, of which 4.5 million Euros and 1.6 million Euros occurred in men and women, respectively.

\section{Discussion}

In this register study of four types of head and neck cancers, we found that nearly 1000 new cases of these cancers are diagnosed annually, with associated costs to the hospital sector of 31.6 million Euros per year (23.4 million Euros per year for men and 8.2 million Euros per year for women). Head and neck cancers related to HPV were found to have an average cost to the hospital sector of 6.1 million Euros per year. As the Danish health care registers comprise comprehensive individual level data with good data quality, we would expect that all incident patients during 2004-2007 are included in this analysis.

In comparison to the current data, the total cost of cervical cancer (not including precancerous lesions) in the Danish hospital sector was estimated to be 10.2 million Euros per year (2008 price level, estimated on the basis of Olsen et al. (2010) [20]) and the total cost of anogenital cancer in the hospital sector to be 7.6 million Euros per year [21]. In addition to these cancer types, genital warts (which may be preventable with the quadrivalent HPV vaccine) cost the health care sector costs an estimated 8.0 million Euros per year (2008 price level) [20]. It should also be noted that recurrent respiratory papillomatosis is partially preventable with the quadrivalent HPV vaccine. However, no Danish studies have yet been undertaken reporting the costs of this respiratory disease.

Our results suggest that the total average cost per patient is especially high for hypopharynx cancer-and particularly in women $(40,951 €)$. In comparison, the total average cost per patient with cervical cancer is $25,546 €$ [20]. International publications on the cost-of-illness of head and neck cancers are limited. The present cost estimates are markedly higher than the findings of Borget et al. (2011) [12] and St. Guily et al. (2010) [3], but are similar to US cost estimates presented by $\mathrm{Hu}$ and Goldie (2008) [22]. International comparisons are complicated by differences in cost levels (e.g. wage levels for health professionals), health care organisation and practice, methodological approach (e.g. prevalent vs incident cases) and time horizon for the analysis (longitudinal vs cross-

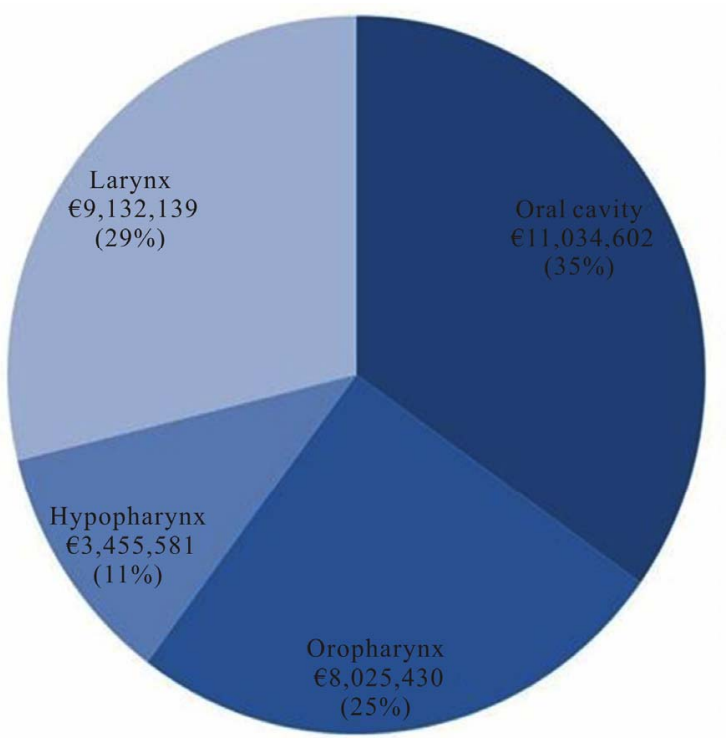

Figure 2. Total cost in Denmark and distribution of the total cost of the four types of head and neck cancers (hospital sector perspective), 2008 price level. 
Table 1. Total average cost per patient and total cost in Denmark of four head and neck cancers (hospital sector perspective), 2008 price level.

\begin{tabular}{|c|c|c|c|}
\hline & Total average cost per patient ${ }^{*}, €$ & Total cost per year, $€$ & $\begin{array}{c}\text { Total cost per year attributable to } \\
\text { HPV16 \& 18, } €^{* *}\end{array}$ \\
\hline Oral cavity—all persons & 30,315 & $11,034,602$ & $1,765,536$ \\
\hline -men & 32,286 & $7,482,196$ & $1,197,151$ \\
\hline —women & 26,762 & $3,552,407$ & 568,385 \\
\hline Oropharynx_all persons & 35,828 & $8,025,430$ & $2,025,538$ \\
\hline -men & 35,862 & $5,800,728$ & $1,464,046$ \\
\hline —women & 35,663 & $2,220,009$ & 560,308 \\
\hline Hypopharynx_-all persons & 39,268 & $3,455,581$ & 634,465 \\
\hline -men & 38,785 & $2,714,952$ & 498,482 \\
\hline —women & 40,951 & 737,119 & 135,339 \\
\hline Larynx—all persons & 35,259 & $9,132,139$ & $1,676,715$ \\
\hline -men & 35,258 & $7,430,542$ & $1,364,292$ \\
\hline —women & 35,458 & $1,710,848$ & 314,122 \\
\hline Total costs, head \& neck cancer & - & $31,647,752$ & $6,102,256$ \\
\hline
\end{tabular}

$3 \%$ discount rate was applied; $€ 1.00=$ DKK $7.45 .{ }^{*}$ i.e. sum of cost estimates for 1 year before and 1 st, 2nd \& 3rd years after diagnosis, with adjustment for deaths during observation period and discounting of future costs (in 2nd \& 3rd years). ** Based on data for percentage of cancers related to HPV16/18 (cf. Table 4).

Table 2. Mean incidence of four head and neck cancers in Denmark (2004-2007).

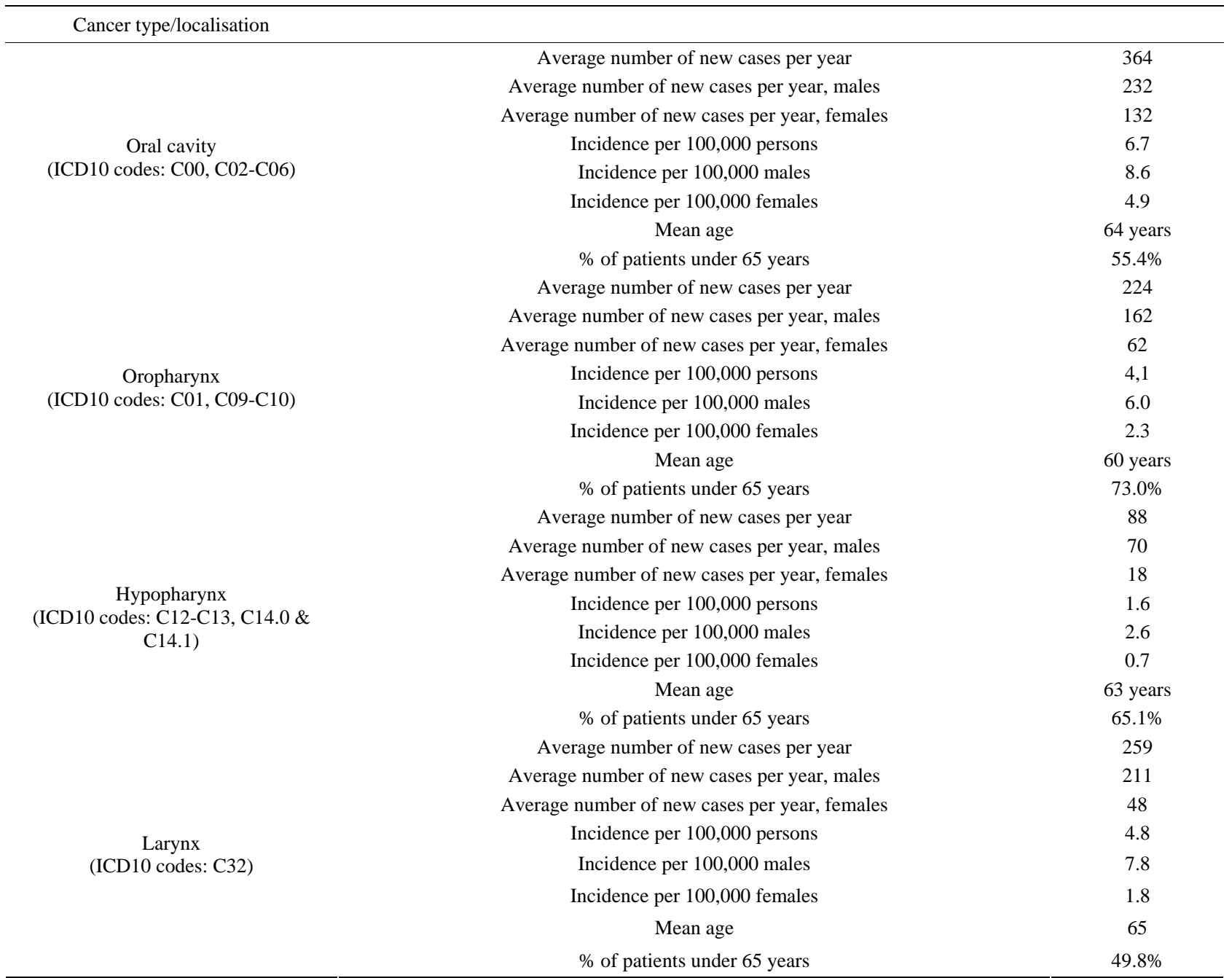


Table 3. Mean annual cost per patient of four types of head and neck cancers (hospital sector perspective), 2008 price level.

\begin{tabular}{|c|c|c|c|c|}
\hline & $\begin{array}{l}\text { Cost the year before time } \\
\text { of diagnosis* }, €(95 \% \text { CI) }\end{array}$ & $\begin{array}{l}\text { Cost } 1 \text { st year }{ }^{* *}, € \\
(95 \% \mathrm{CI})\end{array}$ & $\begin{array}{l}\text { Cost 2nd year**, } \\
\quad(95 \% \mathrm{CI})\end{array}$ & $\begin{array}{c}\text { Cost 3rd year }^{* *}, € \\
(95 \% \mathrm{CI})\end{array}$ \\
\hline \multirow{2}{*}{$\begin{array}{l}\text { Oral cavity } \\
\text { —all persons }\end{array}$} & 3713 & 18,254 & 6941 & 5903 \\
\hline & (3187 - 4318) & $(15,303-21,771)$ & $(6011-8012)$ & $(4916-7083)$ \\
\hline \multirow{2}{*}{ —men } & 3919 & 19,393 & 7339 & 6500 \\
\hline & $(3225$ - 4746) & $(15,513-24,237)$ & $(6146-8761)$ & $(5161-8181)$ \\
\hline \multirow{2}{*}{ —women } & 3371 & 16,251 & 6174 & 4752 \\
\hline & $(2636-4287)$ & $(12,206-21,626)$ & $(4839-7876)$ & (3554 - 6339) \\
\hline \multirow{2}{*}{$\begin{array}{l}\text { Oropharynx } \\
\text { —all persons }\end{array}$} & 3628 & 23,093 & 7185 & 6522 \\
\hline & $(3068$ - 4267) & $(19,316$ - 27,603) & $(6127-8811)$ & (5334 - 7973) \\
\hline \multirow{2}{*}{ —men } & 3571 & 22,888 & 7348 & 6819 \\
\hline & $(2962$ - 4269) & $(18,515$ - 28,137) & $(6127-8811)$ & $(5389$ - 8629) \\
\hline \multirow{2}{*}{ —women } & 3783 & 23,648 & 6744 & 5590 \\
\hline & $(2629-5397)$ & $(16,601-33,662)$ & (4821 - 9428) & $(3963-7881)$ \\
\hline \multirow{2}{*}{$\begin{array}{l}\text { Hypopharynx } \\
\text { —all persons }\end{array}$} & 4292 & 25,923 & 9666 & 7754 \\
\hline & (3382 - 5423) & $(20,409-32,918)$ & $(7394-12,635)$ & $(5688-10,566)$ \\
\hline \multirow{2}{*}{ —men } & 4378 & 25,168 & 10,075 & 8,324 \\
\hline & $(3306-5763)$ & $(18,971$ - 33,377) & $(7285-13,932)$ & $(5717-12,106)$ \\
\hline \multirow{2}{*}{ —women } & 4016 & 28,539 & 8439 & 6009 \\
\hline & $(2567-6208)$ & $(18,522$ - 43,944) & $(5348-13,316)$ & $(3595-10,041)$ \\
\hline \multirow{2}{*}{$\begin{array}{l}\text { Larynx } \\
\quad \text { —all persons }\end{array}$} & 3218 & 23,478 & 6614 & 5052 \\
\hline & $(2859-3610)$ & $(19,476-28,297)$ & $(5753-7602)$ & $(4323-5897)$ \\
\hline \multirow{2}{*}{ —men } & 2950 & 23,653 & 6373 & 5483 \\
\hline & $(2611-3312)$ & $(19,124-29,247)$ & $(5492-7392)$ & $(4568-6573)$ \\
\hline \multirow{2}{*}{ —women } & 4374 & 22,787 & 7655 & 3388 \\
\hline & $(3144-6060)$ & $(15,434-33,619)$ & $(5271-11,116)$ & (2577 - 4429) \\
\hline
\end{tabular}

${ }^{*}$ i.e. the cost 0 - 12 months before the date of diagnosis. ${ }^{* *}$ i.e. the average cost 0 - 12 months after the date of diagnosis, the average cost 13 - 24 months after the date of diagnosis for patients alive and the average cost 25 - 36 months after the date of diagnosis for patients alive, respectively. $€ 1.00=$ DKK 7.45 .

Table 4. HPV prevalence in four head and neck cancers.

\begin{tabular}{ccccc}
\hline $\begin{array}{c}\text { Cancer type/ } \\
\text { localisation }\end{array}$ & $\begin{array}{c}\text { Prevalence } \\
\text { (\% of cancers) }\end{array}$ & HPV16 & $\begin{array}{c}\text { Prevalence } \\
\text { (\% of HPV-positive cancers) }\end{array}$ \\
\hline HPV & 16.0 & 68.2 & HPV18 & HPV16/18 \\
Oral cavity & 28.2 & 86.7 & 34.1 & $100 \%{ }^{*}$ \\
Oropharynx & 21.3 & 69.2 & 2.8 & $89.5 \%$ \\
Hypopharynx & 21.3 & 69.2 & 17.0 & $86.2 \%$ \\
Larynx & & & $86.2 \%$ \\
\hline
\end{tabular}

${ }^{*}$ Co-infections are not taken into account. Source: [13].

sectional approach). The strengths of the current study are cost estimation over four years (Borget et al., for example, used a 1-year cross-sectional approach [12]) and the comprehensive national register data.

We based unit cost estimates on DRG charges for in cross-sectional approach). The strengths of the current study are cost estimation over four years (Borget et al., for example, used a 1-year cross-sectional approach [12]) and the comprehensive national register data. Patients stay and DAGS charges for outpatient visits. These charges were the best available proxies for opportunity costs, but may not accurately reflect them. Use of a hospital sector perspective for cost estimation is likely to underestimate the costs of head and neck cancers for 
several reasons. Firstly, we have omitted the productivity costs to society that are associated with head and neck cancers e.g. indirect costs due to patients' absence from work. This may be particularly relevant for patients with oropharyngeal cancer, as a majority $(73.0 \%)$ were still of workforce age (under 65 years) at the time of diagnosis. Secondly, patients with head and neck cancer may have a higher use of primary health care services (e.g. more GP visits) than the general population, but these primary care costs are not included in the analysis. Finally, when the data for this study were obtained, data on cancer incidence (the Danish National Cancer Register) were only available up until 2007. Very recently published data show that the incidence of head and neck cancer in Denmark after 2007 has increased compared to 2004-2007 [1]. Combined with the possibility of increased HPV prevalence in head and neck cancer [23], this suggests that the costs estimates presented here for the four types of head and neck cancers are underestimates.

The estimated numbers of cancers attributable to HPV infection are associated with some uncertainty. Firstly, there may be misclassifications in the ICD10 coding, leading to an imprecise incidence of the specific cancer types. Secondly, the HPV prevalence data in hypopharyngeal and laryngeal cancer is based on pooled data [13], possibly resulting in inexact number of cases of HPVrelated hypopharyngeal and laryngeal cancer. Näsman et al. (2009) [23] estimated HPV prevalence in tonsillar cancer to be higher than the prevalences presented in Table 1; these same authors reported that HPV prevalence is increasing [23]. Results from a Danish study on HPV prevalence in head and neck cancer have not yet been published.

Even with the current Danish vaccination program (i.e. routine vaccination of pre-adolescent girls) a future decrease in the incidence of head and neck cancer may be expected. However, the clinical significance of this study among others is that vaccination of males as well should be considered when the morbidity and the economic burden of the HPV associated head and neck cancers are taken in to account.

Although cervical disease is responsible for most of the cost burden associated with HPV-related disease, the contribution of non-cervical disease is still considerable. This is especially relevant in view of an increasing incidence of some head and neck cancers, despite a decreasing prevalence of historical risk factors (such as smoking for oropharyngeal cancer $[24,25])$. The current study provides the first Danish estimates of the costs associated with non-cervical and non-genital HPV-related cancers based on very reliable, individual-based data. The cost of head and neck cancers in Denmark is estimated to be 31.6 million Euros per year, and it is expected that the HPV vaccination programme that is now in place will reduce this burden. Future cost-effectiveness studies of the Danish HPV vaccination programme should include the impact of the vaccine's protection against head and neck cancers.

\section{Acknowledgements}

This study was supported by an unrestricted research grant to CAST, University of Southern Denmark, from Sanofi Pasteur MSD. We thank Claire Gudex for language editing of the manuscript.

\section{REFERENCES}

[1] National Board of Health, “The Cancer Register 2010 [Tal og Analyse: Cancerregisteret 2010],” National Board of Health, 2011.

[2] A. Jemal, F. Bray, M. M. Center, J. Ferlay, E. Ward and D. Forman, "Global Cancer Statistics,” CA: Cancer Journal for Clinicians, Vol. 61, No. 2, 2011, pp. 69-90. doi:10.3322/caac.20107

[3] J. L. St Guily, I. Borget, A. Vainchtock, V. Remy and C. Takizawa, "Head and Neck Cancers in France: An Analysis of the Hospital Medical Information System (PMSI) Database," Head \& Neck Oncology, Vol. 2, 2010, p. 22. doi:10.1186/1758-3284-2-22

[4] E. M. Sturgis and P. M. Cinciripini, "Trends in Head and Neck Cancer Incidence in Relation to Smoking Prevalence: An Emerging Epidemic of Human PapillomavirusAssociated Cancers?" Cancer, Vol. 110, No. 7, 2007, pp. 1429-1435. doi:10.1002/cncr.22963

[5] M. Hashibe, P. Brennan, S. C. Chuang, et al., "Interaction between Tobacco and Alcohol Use and the Risk of Head and Neck Cancer: Pooled Analysis in the International Head and Neck Cancer Epidemiology Consortium,” Cancer Epidemiology, Biomarkers \& Prevention, Vol. 18, No. 2, 2009, pp. 541-550.

doi:10.1158/1055-9965.EPI-08-0347

[6] M. B. Gillespie, S. Rubinchik, B. Hoel and N. Sutkowski, "Human Papillomavirus and Oropharyngeal Cancer: What You Need to Know in 2009," Current Treatment Options in Oncology, Vol. 10, No. 5-6, 2009, pp. 296-307. doi:10.1007/s11864-009-0113-5

[7] S. Marur, G. D’Souza, W. H. Westra and A. A. Forastiere, "HPV-Associated Head and Neck Cancer: A Virus-Related Cancer Epidemic,” The Lancet Oncology, Vol. 11, No. 8, 2010, pp. 781-789. doi:10.1016/S1470-2045(10)70017-6

[8] M. L. Gillison, G. D’Souza, W. Westra, et al., "Distinct Risk Factor Profiles for Human Papillomavirus Type 16Positive and Human Papillomavirus Type 16-Negative Head and Neck Cancers," Journal of the National Cancer Institute, Vol. 100, No. 6, 2008, pp. 407-420. doi:10.1093/jnci/djn025

[9] P. M. Weinberger, Z. Yu, B. G. Haffty, et al., "Molecular Classification Identifies a Subset of Human Papillomavirus-Associated Oropharyngeal Cancers with Favorable Prognosis,” Journal of Clinical Oncology, Vol. 24, No. 5, 2006, pp. 736-747. doi:10.1200/JCO.2004.00.3335 
[10] R. R. Laborde, V. Novakova, K. D. Olsen, J. L. Kasperbauer, E. J. Moore and D. I. Smith, "Expression Profiles of Viral Responsive Genes in Oral and Oropharyngeal Cancers," European Journal of Cancer, Vol. 46, No. 6, 2010, pp. 1153-1158. doi:10.1016/j.ejca.2010.01.026

[11] J. M. Lee, M. Turini, M. F. Botteman, J. M. Stephens and C. L. Pashos, "Economic Burden of Head and Neck Cancer. A Literature Review," The European Journal of Health Economics, Vol. 5, No. 1, 2004, pp. 70-80. doi:10.1007/s10198-003-0204-3

[12] I. Borget, L. Abramowitz and P. Mathevet, "Economic Burden of HPV-Related Cancers in France,” Vaccine, Vol. 29, No. 32, 2011, pp. 5245-5249. doi:10.1016/j.vaccine.2011.05.018

[13] A. R. Kreimer, G. M. Clifford, P. Boyle and S. Franceschi, "Human Papillomavirus Types in Head and Neck Squamous Cell Carcinomas Worldwide: A Systematic Review," Cancer Epidemiology, Biomarkers \& Prevention, Vol. 14, No. 2, 2005, pp. 467-475. doi:10.1158/1055-9965.EPI-04-0551

[14] M. Kruse and T. Christiansen, "Register-Based Studies of Healthcare Costs,” Scandinavian Journal of Public Health, Vol. 39, Supplement 7, 2011, pp. 206-209. doi:10.1177/1403494811404277

[15] H. A. Glick, J. A. Doshi, S. S. Sonnad and D. Polsky, "Analyzing Cost. Economic Evaluation in Clinical Trials,” Oxford University Press, Oxford, 2007.

[16] J. Lipscomb, M. Ancukiewicz, G. Parmigiani, V. Hasselblad, G. Samsa and D. B. Matchar, "Predicting the Cost of Illness: A Comparison of Alternative Models Applied to Stroke," Medical Decision Making, Vol. 18, Supplement 2, 1998, pp. S39-S56. doi:10.1177/0272989X9801800207

[17] D. K. Blough, C. W. Madden and M. C. Hornbrook, "Modeling Risk Using Generalized Linear Models," Journal of Health Economics, Vol. 18, No. 2, 1999, pp. 153-171. doi:10.1016/S0167-6296(98)00032-0

[18] M. A. Olsen, A. M. Butler, D. M. Willers, G. A. Gross, B.
H. Hamilton and V. J. Fraser, "Attributable Costs of Surgical Site Infection and Endometritis after Low Transverse Cesarean Delivery,” Infection Control and Hospital Epidemiology, Vol. 31, No. 3, 2010, pp. 276-282. doi:10.1086/650755

[19] Ministry of Health and Prevention, National Board of Health, "[Ministeriet for Sundhed og Forebyggelse, Sundhedsstyrelsen]: Charges 2008-instructions [Takstsystem 2008-Vejledning],” Copenhagen, 2008.

[20] J. Olsen and M. R. Jepsen, "Human Papillomavirus Transmission and Cost-Effectiveness of Introducing Quadrivalent HPV Vaccination in Denmark," International Journal of Technology Assessment in Health Care, Vol. 26, No. 2, 2010, pp. 183-191. doi:10.1017/S0266462310000085

[21] J. Olsen, T. R. Jørgensen, K. Kofoed and H. K. Larsen, "Incidence and Cost of Anal, Penile, Vaginal and Vulva Cancer in Denmark,” BMC Public Health, Vol. 12, 2012, p. 1082. doi:10.1186/1471-2458-12-1082

[22] D. Hu and S. Goldie, “The Economic Burden of Noncervical Human Papillomavirus Disease in the United States,” American Journal of Obstetrics \& Gynecology, Vol. 198, No. 5, 2008, pp. 500-507. doi:10.1016/j.ajog.2008.03.064

[23] A. Nasman, P. Attner, L. Hammarstedt, et al., "Incidence of Human Papillomavirus (HPV) Positive Tonsillar Carcinoma in Stockholm, Sweden: An Epidemic of ViralInduced Carcinoma?” International Journal of Cancer, Vol. 125, No. 2, 2009, pp. 362-366. doi:10.1002/ijc.24339

[24] L. Hammarstedt, D. Lindquist, H. Dahlstrand, et al., "Human Papillomavirus as a Risk Factor for the Increase in Incidence of Tonsillar Cancer," International Journal of Cancer, Vol. 119, No. 11, 2006, pp. 2620-2623. doi:10.1002/ijc.22177

[25] S. Syrjanen, "HPV Infections and Tonsillar Carcinoma," Journal of Clinical Pathology, Vol. 57, No. 5, 2004, pp. 449-455. doi:10.1136/jcp.2003.008656 